\title{
Risk factors of pre-diabetes among adult Nigerians with essential hypertension in a resource-constrained setting of a primary care clinic in eastern Nigeria
}

\author{
Gabriel Uche Pascal Iloh", *, Ndubueze Richard Uchenna ${ }^{2}$, Nnadozie Paul Obiegbu ${ }^{3}$ \\ ${ }^{1}$ Department of Family Medicine, Federal Medical Centre, Umuahia, Abia state, Nigeria \\ ${ }^{2}$ Department of Family Medicine, Federal Medical Centre, Owerri, Imo state, Nigeria \\ ${ }^{3}$ Ministry of Health, Awka, Anambra State, Nigeria and Trainer in Family Medicine Residency, Federal Medical Centre, Owerri, and \\ Umuahia, Nigeria
}

Email address:

ilohgup2009@yahoo.com(G. U. P. Iloh)

To cite this article:

Gabriel Uche Pascal Iloh, Ndubueze Richard Uchenna, Nnadozie Paul Obiegbu. Risk Factors of Pre-Diabetes among Adult Nigerians with Essential Hypertension in a Resource-Constrained Setting of a Primary Care Clinic in Eastern Nigeria. American Journal of Health Research. Vol. 1, No. 3, 2013, pp. 56-64. doi: 10.11648/j.ajhr.20130103.14

\begin{abstract}
Background: As the case detection of pre-diabetes(PD) increases worldwide, screening for its risk factors which overlap with those of type 2 diabetes mellitus(DM) is an important primary care challenge that is often neglected especially in under-resourced setting. Aim: This study was designed to determine the prevalence and risk factors of prediabetes among adult Nigerians with essential hypertension in a resource-constrained setting of a primary care clinic in Eastern Nigeria. Materials and Methods: A cross-sectional study carried out on 320 consecutive adult Nigerians with essential hypertension who were screened for PD and 106 of them who had PD and met the inclusion criteria were age and sex matched with 106 non-hypertensive and non-diabetic control. Demographic and some risk factors of PD were obtained using a pretested, structured and interviewer-administered questionnaire. Pre-diabetes was defined as fasting plasma glucose of 100-125 mg/dL and /or plasma glucose level of 140-199 mg/dL two hours after a $75 \mathrm{~g}$ oral glucose load. Results: One hundred and six $(33.1 \%)$ out of the 320 hypertensive patients screened had PD. Obesity $(\mathrm{P}=0.001)$, positive family history of DM $(\mathrm{P}=0.001)$ and inadequate physical activity $(\mathrm{P}=0.001)$ were significantly associated with $\mathrm{PD}$. The most significant predictor of $\mathrm{PD}$ was obesity $(\mathrm{OR}=12.50(2.38-34.48), \mathrm{P}=0.001)$. The obese patients were twelve and half times more likely to have PD compared to their non-obese counterparts. Conclusion: There was high prevalence of PD in adult hypertensive study population. Obesity, family history of DM and inadequate physical activity were proximate independent risk factors. The presence of these risk factors should therefore provide guide for screening adult Nigerians with essential hypertension for PD in primary care.
\end{abstract}

Keywords: Adult, Hypertension, Nigeria, Pre-Diabetes, Primary Care, Risk Factors

\section{Introduction}

Hypertension co-existing with diabetes mellitus have received the greatest global attention in the last two decades.[1,2] Both conditions are the most common cause of morbidity and mortality from non-communicable diseases in Africa.[3] The number of people living with diabetes currently is 240 million globally and over 7 million in Africa.[1] These populations are about a quarter and a third of the corresponding number of hypertensive patients in Africa, and the world respectively.[1] Diabetes mellitus (DM) is the most common metabolic disorder in
Nigeria and its prevalence has been rising at an alarming rate in the last two decades.[4-6] This carries with it a concomitant increase in the prevalence of diabetic complications resulting in increased morbidity and mortality.

Pre-diabetes is a medical condition in which the blood glucose level is higher than the normal value but not high enough to meet the criteria for the diagnosis of diabetes mellitus.[7] It is characterized by fasting plasma glucose $100-125 \mathrm{mg} / \mathrm{dL}$ and/or plasma glucose level $140-199$ $\mathrm{mg} / \mathrm{dL}$ two hours after a $75 \mathrm{~g}$ oral glucose load.[8] These conditions are known as impaired fasting glucose (IFG) and impaired glucose tolerance (IGT) respectively. Although 
individuals with impaired fasting glucose and/or impaired glucose tolerance do not meet criteria for diabetes mellitus, they are at substantial risk for developing diabetes mellitus and cardiovascular diseases.[9-11]

As the prevalence of diabetes mellitus increases worldwide, $[1,11]$ so will the prevalence of pre-diabetes increase since the latter is a phase in the natural history of diabetes mellitus.[10,12] In United States of America, a prevalence of pre-diabetes of $25 \%$ was reported in US adults and only $4 \%$ of them were aware of the medical condition. [13] In another study in United States of America, Shobha et al, [14] reported prevalence of $9.7 \%$ for impaired fasting glucose and $15.6 \%$ for impaired glucose tolerance in their study of US adults aged $40-74$ years while Lorna et al,[15] reported a prevalence of impaired fasting glucose of $23.5 \%$ among New York City adults. In Canada, a prevalence of pre-diabetes of $3.5 \%$ was reported among primary care patients.[11] Shuqian et al,[16] in a study on the prevalence of diabetes mellitus and IFG in Chinese adults found an IFG prevalence of $4.9 \%$. Shrestha et $a l,[17]$ reported a prevalence of $43 \%$ among hypertensive patients in urban Nepal. In other African countries such as Seychelles, prevalence of impaired fasting glucose of $24.2 \%$ and impaired glucose tolerance of $10.4 \%$ were reported among the study population.[18] In Nigeria, a prevalence of pre-diabetes of $25 \%$ was reported among hypertensive patients in a teaching hospital in Enugu, Nigeria.[4] and 39.1\% reported in a tertiary hospital in Calabar, Nigeria.[19]

Research has identified a number of risk factors for type 2 diabetes mellitus and cardiovascular diseases. [1,2,20] However notable publications have shown that pre-diabetes share similar risk factors with DM. [4,8,17-20] This is not surprising given the fact that pre-diabetes is a phase in the natural history of DM. $[8,15]$ The constitutional risk factors are ageing and family history of diabetes mellitus while the non-constitutional risk factors include obesity, physical inactivity, excessive alcohol ingestion, tobacco use among others. [23] The reported risk factors of diabetes considerably overlap with those of pre-diabetes. [24,25] The presence of these risk factors in adult hypertensive patients is important in screening intervention for prediabetes in primary care settings. It is therefore quintessential to detect early the addition of pre-diabetes on primary hypertension as these may affect morbidity and mortality outcome.

There is paucity of studies on the risk factors of prediabetes in primary care settings in Nigeria. This might be due to the fact that pre-diabetes is a relatively new concept in medical practice. Screening high risk adult hypertensive patients specifically for pre-diabetes and its risk factors is a primary care clinic imperative as persons with pre-diabetes are at increased risk for the development of cardiovascular complications independent of progression to diabetes mellitus [21,20,26] Optimal targeting of intervention for pre-diabetes requires adequate knowledge of the triggers and predictors of pre-diabetes. These predictors if not targeted for intervention in primary care setting may result in development of frank diabetes mellitus. This type of study has not been carried out in the study area thus there is a knowledge gap regarding pre-diabetes and its risk factors among adult hypertensive patients in primary care setting. The findings of this study would help to bridge this gap and early detection and intervention may alter cardiovascular endpoints. Pre-diabetes increases the risk of diabetes mellitus in hypertensive patients and both undiagnosed prediabetes and diabetes are associated with diabetic complications and risk factors. [8,9,20] The authors therefore sought to study the risk factors of pre-diabetes among adult Nigerians with essential hypertension in resource-constrained setting of a primary care clinic in Eastern Nigeria.

\section{Materials and Methods}

\subsection{Ethical Consideration}

Ethical certificate was obtained from the Ethics Committee of the hospital. Informed written consent was also obtained from patients included in the study.

\subsection{Study Design}

This was a clinic-based cross-sectional analytic study carried out from February 2011 to June 2011. A total of 320 consecutive adult Nigerians with essential hypertension were screened for pre-diabetes and one hundred and six of them who had pre-diabetes and met the inclusion criteria were age and sex matched with one hundred and six nonhypertensive and non-diabetic control group at the department of Family Medicine of Federal Medical Centre, Owerri, a tertiary hospital in Imo State, South-eastern, Nigeria.

\subsection{Study Setting}

Owerri is the capital of Imo State, South-east Nigeria. The State is endowed with abundant mineral and agricultural resources with supply of professional, skilled, semi-skilled and unskilled manpower. Economic and social activities are low compared to industrial and commercial cities such as Onitsha, Port Harcourt and Lagos in Nigeria. Until recently, the capital city and its environ have witnessed an upsurge in the number of banks, hotels, schools, markets, industries, junk food restaurants in addition to the changing dietary and social lifestyles.

Federal Medical Centre, Owerri is located in the municipal city of Owerri. It is a tertiary hospital established with the tripartite mandate of service delivery, training and research and serves as a referral centre for primary and secondary public health institutions as well as missionary and private hospitals in Imo State and neighbouring States of Abia, Ebonyi, Rivers and Akwa Ibom States of Nigeria.

The department of Family Medicine serves as a primary 
care clinic within the tertiary hospital setting of the Medical Centre. All adult patients excluding those who need emergency health care services, paediatric patients and antenatal women are first seen at the department of Family Medicine where diagnoses are made. Patients who need primary care are managed and followed up in the clinic while those who need other specialists care are referred to the respective core specialist clinics for further management. The clinic is run by consultant Family Physicians and postgraduate resident doctors in Family Medicine.

\subsection{Study Population}

The study population was made up of one hundred and six out of 320 adult hypertensive patients who had prediabetes and met the inclusion criteria. This category of patients constituted the cases. The control population was also selected from the primary care clinic of the hospital and was made up of one hundred and six non-hypertensive and non-diabetic patients.

The control group was matched for age and sex with the cases. The matching for the age was based on age group matching as in the case category. The control population was subjected to the same screening test for pre-diabetes. The cases and control were studied simultaneously during the period

\subsection{Inclusion and Exclusion Criteria for the Cases}

The inclusion criteria were patients with essential hypertension aged $\geq 18$ years who gave informed written consent for the study. The exclusion criteria included pregnant patients, diabetic patients, patients who had ascites and other forms of oedema and physical deformities affecting the spine and/or the limbs who could not stand for height and weight anthropometric measurements and critically ill patients.

\subsection{Sample Size Determination}

The sample size $(\mathrm{N})$ was calculated using the formula for comparative study [27] $\mathrm{N}=[(\mathrm{Z} \alpha+Z \beta) \times 2 \mathrm{pq}] / \mathrm{d}^{2}$ Where $\mathrm{N}=$ Desired sample size, $\mathrm{Z}=$ The standard normal deviate set at 1.96 which correspond to $95 \%$ confidence level. $\mathrm{P}=$ the prevalence of pre-diabetes in hypertensive patients of $25 \%$ from a previous study in Enugu, Nigeria.[4] $\mathrm{q}=1.0-$ $\mathrm{p}$, and $\mathrm{d}=$ degree of precision desired set at 0.05 The level of significance was set at $5 \%(\alpha=0.05)$ while the power of the $\operatorname{study}(1-\beta)$ was set at $80 \%$. $N=[(1.96 \times 0.05+1.96 \times 0.2) \times$ $2 \times 0.25 \times 0.75] / 0.05^{2}$. Therefore, $\mathrm{N}=74$

The calculated minimum sample size was 74 . However, to improve the precision of the study, the estimated sample size $=\mathrm{Ns}$ was determined considering an anticipated response rate of $90 \%(0.9)$. The estimated sample size $(\mathrm{Ns})$ was determined by dividing the original calculated sample size $(\mathrm{N})$ by the anticipated response rate ${ }^{[28]}$ as follows, $\mathrm{Ns}=$ $\mathrm{N} / 0.9$, where $\mathrm{N}=$ Minimum calculated sample size, $\mathrm{Ns}=$ Selected sample size, anticipated response rate $=0.9$.
Thus, the estimated sample size $=74 / 0.9=82$. However, a sample size of 106 patients was used based the proposed duration of the study.

\subsection{Sampling Technique}

Sample selection was done consecutively based on the inclusion criteria for the hypertensive cases. The control group was selected simultaneously based on those that met the matching criteria with the cases.

\subsection{Diagnostic Procedures}

The weight was measured in kilograms with patients standing bare feet in their minimal clothing and with their pockets free of objects that might add to their weights such as mobile phones, wallets, keys, rings etc using prevalidated stadiometer combined with weighing scale by Techmel and Techmel USA (ZT-120) measured to the nearest $0.1 \mathrm{Kg}$. The weighing scale was checked with $10 \mathrm{Kg}$ standard weight every morning before use and the zero mark was checked after each measurement. ${ }^{[6]}$ In measuring the height, the patient who was barefooted and without head-gear or cap stood against the stadiometer on the weighing scale with the Achilles, gluteus and occiput touching it. A pointer was pressed firmly against the scalp and the measurement read off on the scale in meters to the nearest $0.5 \mathrm{~cm}$. The body mass index was estimated by dividing measured weight in kilograms by the height in meters squared.

The blood pressure was measured using auscultatory method with standard mercury in glass Accuson sphygmomanometer.[6] Prior to the measurement, the patient was seated and rested for 5 minutes [31] in sitting position on a chair that supported the back comfortably. The left arm muscles were relaxed and the forearm was supported with the cubital fossa at the heart level. A cuff of suitable size was applied evenly to the exposed arm. The cuff was rapidly inflated until the manometer reading was about $30 \mathrm{mmHg}$ above the level at which the pulse disappeared and then slowly deflected. During this time, the Korotkoff sounds were monitored using a Litman stethoscope placed over the brachial artery. The systolic blood pressure was noted at the pressure at which the first heart sounds were heard(Korotkoff phase I). The diastolic blood pressure was taken as the pressure at the point when the heart sounds disappeared(Korotkoff phase v). The blood pressure was also measured in the right arm as described for the left arm in order to rule out significant inter-arm blood pressure difference and the arm that gave the higher reading was subsequently used. [31] The systolic and diastolic blood pressures were measured twice separated by an interval of 2 minutes. [31] The three readings were recorded and the mean value was calculated.

The blood glucose was determined after an overnight fast between 8.00 hours to 10.00 hours.[6] After adequate disinfection of the skin over the venepuncture site, 2 millilitres of venous blood sample was drawn from the 
cases and control group for fasting glucose estimation. The cases and control were thereafter given $75 \mathrm{~g}$ anhydrous glucose dissolved in $250 \mathrm{mls}$ of water to drink over 5 minutes. Two millilitres of venous blood sample was collected in the same manner two hours after the glucose load. The plasma glucose estimations were determined by the glucose oxidase method.

\subsection{Diagnostic Criteria}

The fasting blood glucose results were grouped as normal fasting blood glucose $(60-99 \mathrm{mg} / \mathrm{dL})$, impaired fasting glucose $(100-125 \mathrm{mg} / \mathrm{dL})$ and diabetes mellitus $(\geq$ $126 \mathrm{mg} / \mathrm{dL}$ ). The two hours oral glucose tolerance test was classified as $60-139 \mathrm{mg} / \mathrm{dL}$ (normal), $140-199 \mathrm{mg} / \mathrm{dL}$ (impaired glucose tolerance) and $\geq 200 \mathrm{mg} / \mathrm{dL}$ diabetes mellitus).

The body mass index $\geq 30 \mathrm{~kg} / \mathrm{m} 2$ was taken as the definition of obesity with the following categorization: Grade I obesity (mild obesity)=body mass index of 30-34.9, grade II obesity (moderate obesity)=body mass index of 3539.9 and grade III obesity (severe obesity)=body mass index of $\geq 40$. [6]

\section{Methods}

Data collection tool had two sections: clinical data collection schedule section which contained information on clinical parameters such as blood pressure measurement, blood glucose estimation and body mass index and questionnaire section on basic demographic and behavioural variables. The questionnaire tool was adapted from the generic WHO-STEPS instrument approach to surveillance of chronic non-communicable diseases risk factors [29] and was modified and tailored to suit Nigeria environment through review of relevant literature. [4$6,12,20,24,25$, 30-33] The demographic variables collected from the study population included age, sex, marital status, education, occupation, social class and family history of diabetes mellitus. The social classification of patients was into lower, middle and upper occupational classes to suit Nigerian environment.[6] Class I and II belongs to upper class, class III belongs to middle class while class IV and $\mathrm{V}$ belongs to lower class.

The behavioural risk factors evaluated were physical activity, alcohol and cigarette use. The family history of diabetes was coded as yes or no for the presence or absence of diabetes mellitus in the family respectively. Alcohol consumption was classified into non-drinkers, previous drinkers and current drinkers depending on whether the respondents had never taken alcohol in their lifetime drank alcohol in the past but had not used alcohol in the previous 12 months preceding the study or currently used alcohol in the previous 30 days preceding the study respectively. Cigarette smoking status was assessed as non-smokers, previous smokers and current smokers depending on whether the subjects had never used cigarette in their lifetime, took cigarette in the past but had not smoked in the last 12 months preceding the study and currently smoked cigarette within the last one year preceding the study respectively. Physical activity was categorized as active or inactive physical activity. Those engaged in activities that cause a small or large increase in breathing or heart rate are considered physically active and adequate while the level of activity below this was considered inactive physical activity and inadequate. The physical activities were assessed in the previous 30 days. Subject's occupational and activities of daily living were taken into account in assessing for the physical activity.

The pre-testing of the questionnaire was done internally and externally at the primary care clinics of the hospital and Federal Medical Centre, Umuahia, Abia State, Nigeria respectively using ten diabetic patients. The pre-testing of the questionnaire lasted for one week. The respondents for the pre-testing were selected haphazardly from the clinics. The pretesting was done to find out how the questionnaire would interact with the respondents and ensured that there were no ambiguities.

The questionnaire instrument was intervieweradministered. Language used was English Language. However, local language was used to explain verbally to the patients who could not understand the medical language in the questionnaire.

\section{Operational Definitions}

Hypertension was defined as systolic and/or diastolic blood pressures $\geq 140 / 90 \mathrm{mmHg}$ or documented use of antihypertensive medications in a previously diagnosed person with hypertension.[6] Pre-diabetes was defined as fasting plasma glucose of $100-125 \mathrm{mg} / \mathrm{dL}$ and /or plasma glucose level of $140-199 \mathrm{mg} / \mathrm{dL} 2$ hours after a $75 \mathrm{~g}$ oral glucose load. Diagnosis of diabetes mellitus was based on venous plasma glucose of $\geq 126 \mathrm{mg} / \mathrm{dl}$ after an overnight fast which was confirmed by a repeat test on second clinic visit or current use of anti-diabetic medications. Risk factors of pre-diabetes refers to antecedent condition(s) whose presence is(are) positively associated with an increased probability that diabetes will develop later or that the prognosis of an existing pre-diabetes will progressively worse. The risk factors studied included non-modifiable factors of age, sex, family history of diabetes mellitus as well as modifiable factors of obesity, physical inactivity, excessive alcohol use and tobacco use. Primary care refers to the care provided by physicians specifically trained for comprehensive first contact and continuing care for undifferentiated patients including early detection, management of the patient, health promotion and maintenance.

\section{Statistical Analysis}

The results generated were analyzed using software Statistical Package for Social Sciences (SPSS) version 13.0, Microsoft Coperation Inc. Chicago, IL, USA for the 
calculation of percentages for categorical variables and mean for continuous data. Categorical variables were compared by Chi-square test. Logistic regression analysis was done to ascertain the independent risk factors of prediabetes. A p-value of $<0.05$ was considered statistically significant.

\section{Results}

One hundred and six out of a total of 320 hypertensive patients had pre-diabetes giving a prevalence of $33.1 \%$. The age of the hypertensive patients ranged from 18 years to 79 years with a mean age of $52 \pm 11.82$ years while the age of the control group ranged from 18 years to 79 years with mean age of $52 \pm 12.72$ years. Other demographic characteristics of the hypertensive cases and their control group are shown in table 1 .

Table 1: Demographic characteristics of the study population

\begin{tabular}{|c|c|c|}
\hline Variables & $\begin{array}{l}\text { Hypertension group } \\
\text { Number(\%) }\end{array}$ & $\begin{array}{l}\text { Control group } \\
\text { Number(\%) } \\
\end{array}$ \\
\hline \multicolumn{3}{|l|}{ Age } \\
\hline$<30$ & $4(1.3)$ & $4(1.3)$ \\
\hline $30-39$ & $50(15.6)$ & $50(15.6)$ \\
\hline $40-49$ & $94(29.4)$ & $94(29.4)$ \\
\hline $50-59$ & 101(31.6) & 101(31.6) \\
\hline $60-69$ & $50(15.6)$ & $50(15.6)$ \\
\hline$\geq 70$ & $21(6.5)$ & $21(6.5)$ \\
\hline Total & $320(100.0)$ & $320(100.0)$ \\
\hline \multicolumn{3}{|l|}{ Sex } \\
\hline Male & $105(32.8)$ & $105(32.8)$ \\
\hline Female & $215(67.2)$ & $215(67.2)$ \\
\hline \multicolumn{3}{|l|}{ Marital status } \\
\hline Married & $222(69.0)$ & 293(92.0) \\
\hline Single & $23(7.0)$ & $23(7.0)$ \\
\hline Widowed & $67(21.0)$ & $0(0.0)$ \\
\hline Separated & $8(3.0)$ & $4(1.0)$ \\
\hline Total & $320(100.0)$ & $320(100.0)$ \\
\hline \multicolumn{3}{|l|}{ Education } \\
\hline No formal education & $29(9.1)$ & $14(4.4)$ \\
\hline Primary & $121(37.8)$ & $97(30.3)$ \\
\hline Secondary & $81(25.3)$ & $80(25.0)$ \\
\hline Tertiary & $89(27.8)$ & $129(40.3)$ \\
\hline Total & $320(100.0)$ & $320(100.0)$ \\
\hline \multicolumn{3}{|l|}{ Occupation } \\
\hline Student/unemployed & $24(7.5)$ & $2(0.6)$ \\
\hline Trading & $105(32.8)$ & $92(28.8)$ \\
\hline Farming & $44(13.8)$ & $79(24.7)$ \\
\hline Artisans & $21(6.6)$ & $32(10.0)$ \\
\hline Civil servants & $126(39.3)$ & $115(35.9)$ \\
\hline Total & $320(100.0)$ & $320(100.0)$ \\
\hline
\end{tabular}

\begin{tabular}{lll}
\hline Variables & $\begin{array}{l}\text { Hypertension group } \\
\text { Number(\%) }\end{array}$ & $\begin{array}{l}\text { Control group } \\
\text { Number(\%) }\end{array}$ \\
\hline Social class & & \\
Lower & $137(42.8)$ & $113(35.3)$ \\
Middle & $123(38.4)$ & $127(39.7)$ \\
Upper & $60(18.8)$ & $80(25.0)$ \\
Total & $320(100.0)$ & $320(100.0)$ \\
\hline
\end{tabular}

Bivariate analysis of demographic and behavioural variables as related to pre-diabetes showed that family history of $\operatorname{diabetes}\left(\mathrm{x}^{2}=46.11, \mathrm{df}=1, \quad \mathrm{P}\right.$-value $\left.=0.001\right)$, obesity $\left(\mathrm{x}^{2}=17.46, \mathrm{df}=1, \mathrm{P}\right.$-value $\left.=0.001\right)$ and inadequate physical activities $\left(\mathrm{x}^{2}=20.0, \mathrm{df}=1, \mathrm{P}\right.$-value $\left.=0.001\right)$ were statistically significant while other variables were not statistically significant.[Table 2]

Table 2: Some risk factor variables as related to pre-diabetes among the study population

\begin{tabular}{lllll}
\hline $\begin{array}{l}\text { Variables } \\
\text { Number(\%) }\end{array}$ & $\begin{array}{l}\text { Pre-diabetes } \\
\text { Number(\%) }\end{array}$ & Control & $\mathbf{x}^{2}$ & P-value \\
\hline Family history of diabetes & & & \\
Yes & $58(54.7)$ & $38(35.8)$ & & \\
No & $48(45.3)$ & $68(64.2)$ & & $0.001^{*}$ \\
Total & $106(100.0)$ & $106(100.0)$ & 46.11 & \\
Body mass index & & & \\
Obese & $67(63.2)$ & $12(11.3)$ & & \\
Non-obese & $39(36.8)$ & $94(88.7)$ & & \\
Total & $106(100.0)$ & $106(100.0)$ & 17.46 & \\
Physical activity & & & \\
Adequate & $4(3.8)$ & $51(48.1)$ & & \\
Inadequate & $102(96.2)$ & $55(51.9)$ & & \\
Total & $106(100.0)$ & $106(100.0)$ & 20.0 & \\
Alcohol use & & & & \\
Non-use & $49(46.2)$ & $62(58.5)$ & & \\
Moderate & $34(32.1)$ & $17(16.0)$ & & \\
Heavy & $23(21.7)$ & $27(25.5)$ & & \\
Total & $106(100.0)$ & $106(100.0)$ & & \\
Tobacco use & & & & \\
Never use & $85(80.2)$ & $58(54.7)$ & & \\
Past user & $17(16.0)$ & $25(23.6)$ & & \\
Current user & $4(3.8)$ & $23(21.7)$ & & \\
\hline
\end{tabular}

Remark: *=Significant, **Non-significant

However, on logistic regression of the statistically significant variables obesity, family history of diabetes and inadequate physical activities remained statistically significant with obesity being the most significant predictor of pre=-diabetes.[Table 3] A significantly higher proportion of the obese hypertensive patients had prediabetes compared to non obese hypertensive. $(\mathrm{OR}=12.50$, $\mathrm{CI}=2.38-34.48$, P-value $=0.001$ ) The obese hypertensive 
patients were twelve and half times more likely to have prediabetes compared to the non obese hypertensive.

Table 3: Predictors of pre-diabetes among the hypertensive patients

\begin{tabular}{llll}
\hline Variables & Odds ratio & $\begin{array}{l}\text { Confidence } \\
\text { interval (95\%) }\end{array}$ & P-value \\
\hline Body mass index & & & \\
Non-obese & 1.0 & $2.33-34.48$ & 0.001 \\
Obese & 12.50 & & \\
Family history of diabetes & 1.0 & $5.99-170.31$ & 0.001 \\
No & 12.19 & & \\
Yes & 1.0 & & \\
Physical activity & 9.19 & $3.07-27.48$ & 0.001 \\
Adequate & & & \\
Inadequate & & & \\
\hline
\end{tabular}

\section{Discussion}

The prevalence of pre-diabetes among the study population was $33.1 \%$. This is higher than $25 \%$ reported among hypertensive patients in Enugu, Nigeria [4] and 3.5\% reported among primary care patients in Canada.[11] The prevalence of pre-diabetes in this study is lower than $39.1 \%$ reported in Calabar, Nigeria [19] and 43\% reported in Nepal. [17] However, the prevalence of pre-diabetes of $33.1 \%$ in this study is within the range of $25.0 \%-47.0 \%$ reported in the European Study of Hypertension and Diabetes.[34] However, this study has demonstrated the existence of pre-diabetes in essential hypertension which is an issue of phenomenal clinical and public health importance in Nigeria [4,19] and other parts of the world such as Taiwan where pre-diabetes is a rapidly emerging epidemic.[35] This study has buttressed the previous reports that the prevalence of pre-diabetes in essential hypertension in Nigeria is relatively low but is rapidly changing. [4,19] Although pre-diabetes is an intermediate phase in the natural history of type 2 diabetes mellitus but pre-diabetic patients are at increased risk of progressing to type 2 diabetes mellitus and developing cardiovascular complications of diabetes mellitus. [9,24] However, not all hypertensive patients with pre-diabetes will progress to type 2 diabetes mellitus, but their chances of developing type 2 diabetes mellitus are high. [9,12,20] This may be promoted and enhanced by other mutable and immutable risk factors of cardiovascular diseases.[24,25] The finding of this study therefore portends a possible increase in the incidence of type 2 diabetes mellitus among adult Nigerians with essential hypertension and underscores the need to critically assess these patients during clinical encounter in primary care setting for pre-diabetes. This will help to reduce the health costs associated with management of their hypertensive condition and possible concurrent type 2 diabetes mellitus. In these regard, primary prevention intervention for pre-diabetes is a compelling necessity in primary care setting in the study area.
The most significant risk factor of pre-diabetes in this study was obesity. This finding is similar to reports from Nigeria [4,19] and other parts of the world such as Seychelles[18] and Nepal.[36] Hypertension can therefore co-exist with obesity and pre-diabetes and possibly point to a common predisposing or promotional metabolic risk factors under the umbrella of metabolic syndrome. [6] Emerging evidence has suggested that pre-diabetes, hypertension and obesity may be aetiologically and prognostically related through the insulin resistance syndrome which is a cluster of atherogenic cardiovascular risk factors which predict cardiovascular diseases. Although not every obese hypertensive patients are at risk for development of pre-diabetes but their chances are high. Such group of obese hypertensive who may not develop pre-diabetes are probably those with low cardiovascular risk profile.[6] With the changing lifestyle in the study area, obese adult Nigerians with primary hypertension in primary care setting should be committed to lifestyle modification and this should also be recommended for all adult hypertensive patients even those who are not obese. It is therefore quintessential to detect early the addiction of prediabetes on obese hypertensive Nigerians as this may affect the quality of care as well as morbidity and mortality profiles.

A significant association was found between pre-diabetes and a positive family history of diabetes in this study. This finding is consistent with other reports on positive family history of type 2 diabetes mellitus as an important risk factor for development of pre-diabetes.[37,38] This genetic contribution involves multiple genes. However, report has shown that family history of type 2 diabetes was associated with decreased insulin sensitivity and an impaired balance between insulin sensitivity and insulin secretion. [39] As the prevalence of diabetes mellitus increases worldwide so will the family history of diabetes mellitus increases and invariably pre-diabetes since pre-diabetes is a prolonged intermediate phase in the natural history of diabetes mellitus. Interventions to prevent pre-diabetes in hypertensive Nigerians with family history of diabetes should be a compelling primary care priority in the study area. The presence of family history of diabetes mellitus during clinical encounter with hypertensive Nigerians in primary care clinics should provide guide for screening for pre-diabetes. Thus at primary care level, family history of diabetes mellitus may help tailor health promotion, health maintenance and risk reduction messages for this special group of hypertensive patients.[40]

Inadequate physical was found to have a significant association with pre-diabetes. This could be related to the reports that physical inactivity leads to decrease insulin effectiveness and poor utilization of glucose and fats in the body cells.[41-43] Physical inactivity is a one of the documented risk factor for dysglycaemia.[42] These studies [41-43] have demonstrated that prescribing physical exercise for the hypertensive patients poses no threat to their hypertensive condition. Evidence has shown that even 
lower levels of weekly energy expenditure may be associated with health benefits and exercise can be accumulated in one or several sessions and the progression of exercise should be gradual.[43] Health professionals should therefore explain to their hypertensive patients in sufficient details the health impact of physical inactivity. This information should not only be limited to the consequences of physical inactivity but also the benefits of physical activity as an adjunct to medication in lowering blood pressure and also reduces their overall cardiovascular risk.

\section{Implications of the Study}

Disease patterns have been changing in recent decades in Nigeria due to socio-economic development and demographic changes. Non-communicable diseases such as hypertension and diabetes mellitus are implicated for rising morbidity and mortality from cardiovascular diseases in Nigeria and carry great concern for the future. Hypertensive individuals do not just develop diabetes mellitus overnight, they go through a prolonged intermediate phase termed pre-diabetes which at present has been recognized as a phase in the natural history of diabetes mellitus. Research has documented that the rate of progression from pre-diabetes to type 2 diabetes mellitus averages to $10 \%$ annually and pre-diabetic patients may not recover spontaneously from the pre-diabetic state.[8]

The burden of pre-diabetes in patients with essential hypertension should sensitize clinicians to screen high risk hypertensive patients for pre-diabetes and assess them for modifiable and non-modifiable risk factors during clinical encounter in primary care setting. The health providers, managers and policy makers should direct interventional strategies to prevent or at the least slow down the progression of pre-diabetes to overt type 2 diabetes mellitus and its potential complications as envisioned in the WHO global strategy on diet, physical activity and health.[33]

\section{Limitations of the Study}

The authors had certain constraints which imposed some degree of limitations to the absolute generalization of the findings: The limitations imposed by the 'case-control' nature of the study design are recognized by the researchers. Hypertension may antedate the development of prediabetes and vice versa. However, this study stimulates the need for longitudinal studies. This would enable a quasi cause-effect relationship to be drawn and also for a reliable and valid conclusion to be ascertained.

The sample size used was comparatively small, but this was more than the estimated sample size and was the number of patients seen during the approved duration of the study. The sample was drawn from hospital attendees in the study area as only patients who presented to the clinic were studied. Thus extrapolation and generalization of the results of the study to the entire population should be done with utmost caution because the findings may not be a true representation of what may be obtained in the community.

The study didn't exclude hypertensive patients that were on anti-hypertensive medications that affect glucose homeostasis such as $\beta$-blockers and thiazide diuretics among other lifestyle factors that affect glucose metabolism However, reports in Nigeria showed that antihypertensive medications that affect glucose metabolism didn't significantly affect the prevalence of pre-diabetes among hypertensive Nigerians. [19]

More so, the limitations of not matching the hypertensive patients for other socio-demographic characteristics such as occupation, marital status, education and socio-economic class among others are recognized by the authors. This was designed to avoid over-matching on the patients sociodemographic characteristics which might lead to variable degree of systematic error.

Furthermore, the authors didn't measure insulin levels because of absence of facilities for it in the study centre. However, hyperinsulinaemia and insulin resistance are not found in every patient with hypertension and not all patients with hyperinsulinaemia have hypertension.

\section{Conclusion}

This study has demonstrated a high prevalence of prediabetes among the study. Obesity, inadequate physical activity and family history of diabetes mellitus were proximate independent risk factors for pre-diabetes. The presence of these risk factors should therefore provide guide for screening adult Nigerians with essential hypertension for pre-diabetes in primary care. More so, interventions to prevent pre-diabetes in hypertensive patients should be a compelling health priority in primary care settings particularly in resource-constrained environment.

\section{Future Research Direction}

In the study area, further hospital-based and communitybased studies are recommended in order to explore other risk factors of pre-diabetes and its correlates. This will provide valuable clinical and epidemiological data for collaborative purposes.

\section{References}

[1] Wild S, Roglic G, Green A, Sicree R, King H. Global prevalence of Diabetes. Estimates for the year 2000 and projections for 2030. Diabetes Care 2004; 27: 1047-53.

[2] Kearney PM, Whelton M, Reynolds K. Global burden of hypertension- analysis of worldwide data. Lancet 2005; 365 : 217-23.

[3] Unwin N, Setel P, Rashid S, Mugusi F, Mbanya JC, Kitange $\mathrm{H}$, et al. Non-communicable diseases in sub-Saharan Africa: where do they feature in the health research agenda? Bull 
World Health Organ 2001; 79: 947-53.

[4] Ogbu I. S, Neboh C. I. The prevalence of Prediabetes among hypertensive patients in Enugu, Southeast Nigeria. Niger Med J 2009: 50: 14-17.

[5] Iloh GUP, Ofoedu JN, Njoku PU, Amadi AN, Godswill-Uko EU. Blood Glucose Control and Medication Adherence Among Adult Type 2 Diabetic Nigerians Attending A Primary Care Clinic in Under-resourced Environment of Eastern Nigeria. North Am J Med Sci.2012; 4:310-15.

[6] Iloh GUP, Ikwudinma AO, Obiegbu NP. Obesity and Its Cardio-metabolic Co-morbidities Among Adult Nigerians in a Primary Care Clinic of a Tertiary Hospital in SouthEastern Nigeria. J Fam Med Primary Care 2013; 2: 20-26.

[7] Unwin N, Shaw J, Zimmet P, Alberti KG. Impaired glucose tolerance and impaired fasting glycaemia- the current status on definition and intervention. Diabet Med 2002; 19: 708-23.

[8] Ramlo-Halsted BA, Edelman SV. The natural history of type 2 diabetes: Implications for clinical practice. Prim Care 1999; 26): 771-89.

[9] Robinson SJ, Gordon SA, Russell JW, Feldman EL. Microvascular complications of impaired glucose tolerance. Diabetes 2003; 52: 2867-73.

[10] Harris MI, Eastman RC. Early detection of undiagnosed Diabetes mellitus: a US perspective. Diabetes Metab Res Rev 2000; 16: 230-36.

[11] Leiter L.A., Barr A., Belanger A, Labin S, Ross A, Tidesley $\mathrm{H}$ D. et al, Diabetes screening in Canada, (DIASCAN), study. Prevalence of undiagnosed diabetes and glucose intolerance in family physician offices. Diabetes Care 2001; 24: $1038-43$

[12] Shyam SG, Mohammed AA, Kamlesh B, Kalyan KD. Prevalence of pre-hypertension and associated cardiovascular risk profiles among prediabetic Omani adults. BMC Public Health 2008; 8: 108.

[13] Rolka DR, Burrows NR, Li Y, Geiss LS. Self-reported prediabetes and risk-reduction activities-US-2006. JAMA 2009; 301: 591-93.

[14] Shobha SR, Philips S, Tamara M. Impaired glucose tolerance and impaired fasting glucose. Am Fam Physician 2004; 69: 1961-68, 1971-72.

[15] Lorna ET, Ushma DU, Shadi C, Renu G, Diana KB, Charon $\mathrm{G}$ et al. Prevalence and control of diabetes and impaired fasting glucose in New York City. Diabetes Care 2009; 32: $57-62$.

[16] Shuqian L, Wenyu W, Xiaoguang Y, Elisa T, Jian Z, Yuna H et al. Prevalence of diabetes and impaired fasting glucose in Chinese adults, China National Nutrition and Health survey 2002. Prev Chronic Dis 2011; 8(1).

[17] Shrestha UK, Singh DL, Bhattarai MD. The prevalence of hypertension and diabetes defined by fasting and 2 hour plasma glucose criteria in urban Nepal. Diabetes Medicine 2006; 23: 1130-35.

[18] Faeh D, William J, Tappy L, Ravussin E, Bovet P. Prevalence, awareness and control of diabetes in the Seychelles and relationship with excess body weight. BMC Public Health 2007; 7:163.
[19] Essien OE, Peters EJ, Udoh AE, Ekott JU, Odigwe CO. Prevalence and pattern of abnormal glucose tolerance in adult Nigerians with primary hypertension. Niger J Med 2007; 16: 50-56

[20] Tuomilehto J, Lindstron J, Eriksson JG, Valla TT, Hamalainen H, Illane-Parikka $\mathrm{P}$ et al. Prevention of type 2 DM by changes in lifestyle among subjects with impaired glucose tolerance. N Engl J Med 2001; 344: 1343-50.

[21] Kuller LH, Veletgas P, Barzilay J, Beauchamp NJ, 'O' leary DH, Savage PJ. Diabetes mellitus: subclinical cardiovascular disease and risk of incident mortality. Arterioscer Thromb Vasc Biol 2000; 20: 823-29.

[22] The DECODE study: Group for the European Diabetes Epidemiology. Glucose tolerance and cardiovascular mortality: comparison of fasting and two hour diagnostic criteria. Arch Intern Med 2001; 161: 397-405.

[23] Chobanian AV, Bakris GL, Black HR, Cushman WC, Green LA, Izzo JL et al. The seventh report of the Joint National Committee on Prevention, Detection, Evaluation and Treatment of high blood pressure: The JNC VII report. JAMA 2003; 289: 2560- 72 .

[24] Mills JD, Grant PJ. Insulin resistance homeostasis factors and cardiovascular risk. Br J Diabetes Vasc Dis 2000; 2: 1926.

[25] Akintude AA. Epidemiological and conventional cardiovascular risk factors among hypertensive subjects with normal and impaired fasting glucose. S Afr Med J 2010; 100: 594-97.

[26] Cynthia C, Harvey K, Bonita E, Falkner BE. The utility of fasting glucose for detection of prediabetes. Metabolism 2006; 55: 434-38.

[27] Ibrahim T. Sample size determination. In: Research Methodology and Dissertation writing for Health and Allied Health Professionals. Abuja, Nigeria Cress Global Link Limited; 2009: p.70-75.

[28] Araoye MO. Sample size determination. Research Methodology with Statistics for Health and Social Sciences, Ilorin, Nathadex Publishers, 2004. p.115- 21.

[29] WHO. Survey of the STEPwise approach for the survellaince of risk factors for non-communicable diseases, Brazzaville, WHO, Region office for Africa, 2007.

[30] Riddell M, Fowles J. How to treat prediabetes with exercise effectively. Clinical practice guide Diabetes 2010; 10-20.

[31] Onwubere B, Kadiri S. Guidelines for the management of hypertension in Nigeria. Nigerian Hypertension Society. Enugu, Ezu Books Limited 2005.p. 1-40

[32] Iloh GUP, Ofoedu JN, Njoku PU, Amadi AN, Godswill-Uko EU. Medication adherence and blood pressure control amongst adults with primary hypertension attending a tertiary hospital primary care clinic in Eastern Nigeria. African Journal of Primary Health Care \& Family Medicine $2013 ; 5: 446$.

[33] WHO. Global strategy on diet, physical activity and health. Bulletins of the WHO 2006; 5: 16-8.

[34] Govindarajan G, Sowers JR, Stump C. Hypertension and Diabetes Mellitus. European Cardiology 2006; 2: 1-7. 
[35] Chen K, High L. Prevalence of impaired fasting glucose and type 2 diabetes mellitus in Penghu Islets, Taiwan: evidence of a rapidly emerging epidemic. Diab Res Clin Pract 2009; 44: 59-69.

[36] Shanker JH, Mahmood SE, Joshi MC, Shaifali I. Obesity indices amongst diabetics in an urban population of Western Nepal. J. Diabetes Metab 2011; 2:134.

[37] Warburton DER, Nicol CW, Bredin SSD. Health benefits of physical exercise: the evidence. CMAJ 2006; 174: 801-809.

[38] Jeon_CY,LLokken_RP,_Hu_FB, van_Dam_RM. Physical activity of moderate intensity and risk of type 2 diabetes: a systematic review. Diabetes Care 2007; 30: 744-52.

[39] Lee IM, Skerrett PJ. Physical activity and all-cause mortality: what is the dose response relationship? Med Sci Sports Exerc 2001; 33: 459-71.
[40] Oyegbade OO, Abioye-Kuteyi EA, Kolawole BA, Ezeoma IT, Bello IS. Screening for diabetes mellitus in a Nigerian Family Practice Population. Am Fam Pract 2007; 49:15.

[41] Harrison TA, Hindorff LA, Kim H, Wines RC, Bowen DJ, McGrath BB et al. Family history of diabetes as a potential public health tool. Am J Prev Med 2003; 24: 152-59.

[42] Arslanian SA, Bacha F, Saad R, Gungor N. Family history of type 2 diabetes is associated with decreased insulin sensitivity and an impaired balance between insulin sensitivity and insulin secretion in White youth. Diabetes Care 2005; 28: 115-19.

[43] Yoon PW, Scheuner MT, Khoury MJ. Research priorities for evaluating family history in the prevention of common chronic diseases. Am J Prev Med 2003; 24:128-35. 